\title{
A Knowledge Management Closed-loop Architecture for Fundamentals of Computer Technology
}

\author{
Chisong LI \& Min JIANG \\ Network \& Computer Science center, Huazhong University of Science \& Technology, Wuhan, China
}

\begin{abstract}
Fundamental of Computer Technology is a course in first year of college to enhance computer practical skill of undergraduate and provide experiment of computational thinking. There are three issues in fundamental of computer education. One is how to organize mass content of course. The second is how to combine academic education and technical practice in teaching. The last is students on various computer practical skill levels. To guarantee quality of teaching, a closed-loop architecture based on knowledge management is proposed, which can assist teacher to hold over teaching proceeding and arouse students to get knowledge. Then some data contain test scores and investigation results are provided to prove the efficiency of the closed-loop architecture.
\end{abstract}

KEYWORD: Knowledge management; Knowledge map; Computer fundamental; Teaching methodology; Closed-loop; Lab teaching; Tacit knowledge

\section{INTRODUCTION}

In early 1990s, by the development of computer science and enhance of computer application in science major, the basic course system in general education of computer science have been built in many universities to widen the specialty content of student. In the system, "Fundamental of computer technology" is the first course in order of depth. Huazhong University of Science and Technology is among the first Universities joining the national "211 Project" and "985 Project". Fundamental of Computer Technology is a required course for student whose major discipline is not computer science. It is offered in first semester of college. The total amount of students taken the course is above 5000. Fundamental of Computer Technology includes 20 hours curricular teaching and 20 hours experiment operation. A classroom consists of 3 or 4 classes in same major, containing 100 to 130 students.

The objective of the general education of computer science is a hierarchy of three levels. First level is to spread computer culture, second is to train skills of application, the last is development of computer thinking. The goal of Fundamental of Computer Technology covers level one \& level two and reaches level three. In class teaching, there are three issues need to be solved.
1. The content of course almost covers every main field of computer science. When lessons shift from one field to another, students can't keep sequence on study because of discipline boundary. How to organize mass content of course and break discipline boundaries, integrate multi-disciplinary knowledge?

2. Students are on various computer practical skill levels. At the beginning of course, a survey would be conducted to know computer practical skill of students. The result in 2012 and 2014 shows less than 40 percent of student can use Word and PowerPoint to do simple process. How to satisfy every student in teaching and guarantee teaching quality?

3. How to keep balance between academics and technicality in teaching.

\section{KNOWLEDGE MANAGEMENT}

To solve the issues above, we introduced knowledge management in teaching process.

Knowledge partitioned into two parts: explicit knowledge and tacit knowledge. Explicit knowledge can be expressed and recorded in visual and oral means. Explicit knowledge is easy to communicate, store, and distribute. Tacit knowledge is not easily visible and expressible. It is integral to the entirety of a person's consciousness. Explicit knowledge can 
convert to tacit knowledge by systematic steps [1]. Psychology research indicated that tacit knowledge played important role in scientific innovation [2]. Tacit knowledge is acquired largely through association with other people, and requires joint or shared activities to be imparted from on to another [3].Knowledge management are Strategies and processes designed to identify, capture, structure, value, leverage, and share an organization's intellectual assets to enhance its performance and competitiveness[4]. The purpose of knowledge management is knowledge innovation [5]. It is based on two critical activities: capture and documentation of individual explicit and tacit knowledge, and its dissemination within the organization. As far as college teacher concerned, knowledge management is not only a teaching method, but also an effective tool to promote professional level. Many college teachers have no idea about knowledge management at present. Though knowing course content well, they are not good at structuring knowledge points, assessing the knowledge dimension of a course and proposing approach to capture the required knowledge quickly. Ma et al [6] discussed the importance of knowledge management for college teacher. It lists four advantages of knowledge management. First, it can help new teacher in mastering required knowledge and professional skill. Second, it would assist college to formulate training programs for teacher, reinforcing team construction. Third, teachers would clarify the relationships among the knowledge and draft appropriate teaching plan. The last is to enhance utilization of tacit knowledge and knowledge sharing in teachers.

The paper is organized as follows. Section 1 introduces the situation of Fundamental of Computer Technology and the problems in teaching. Section 2 describes the conceptions of knowledge management and its potential for course promotion. Section 3 presents a closed-loop architecture based on knowledge management, and evaluates the architecture by data analysis. Section 4 concludes.

\section{CLOSED-LOOP ARCHITECTURE}

The essence of teaching and learning is imparting and sharing activities of knowledge. In this process, students gain personal experiences. After that, new requests for knowledge are generated. New knowledge integrates to old knowledge system. At the end, personal knowledge system is updated. A successful education process should satisfy it. In practice, we design a closed-loop architecture to solve the three questions presented in section 1 by applying knowledge management to teaching deliberately. The close-loop architecture consists of three stages, illustrated in figure 1.

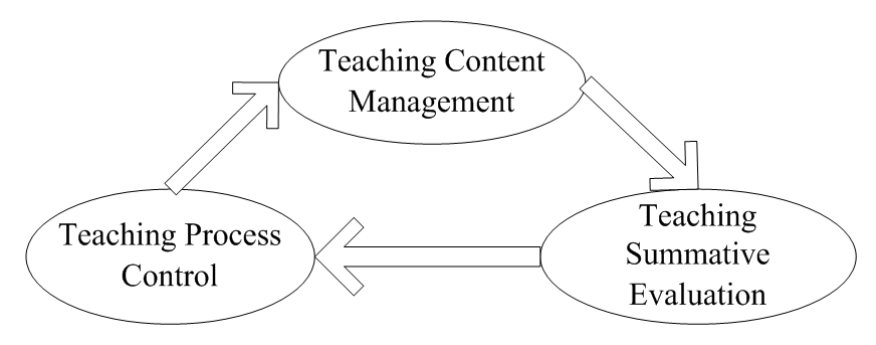

Figure 1. Closed-loop architecture.

First stage is teaching content management, aims at question 1 and question 3. Second stage is teaching process control, aims at question 2. Last stage is teaching summative evaluation, which provides basis for next teaching loop.

\subsection{Teaching content management}

Composed of contents across various major disciplines, Fundamental of Computer Technology is a proper circumstance for knowledge management practice. Course content management emphasizes the internal relationship of knowledge. To communicate each pair of points in course content, it refers to content, identity, classify and structure knowledge. In this stage, the management is performed by teachers. It is realized in two approaches: collective course preparation of teachers and pre-course survey on students.

\subsubsection{Teacher's knowledge management}

Knowledge map is an effective tool for knowledge management, proposed by B. C. Brooks first. He mentioned that a person's knowledge can formulated as a concept map in which a vertex represents a knowledge unit. Knowledge map is not only a guide to knowledge, but also is an organization's internal or external repositories or sources of knowledge [7].

The process oriented knowledge map of Fundamental of Computer Technology is represented by figure 2 . 


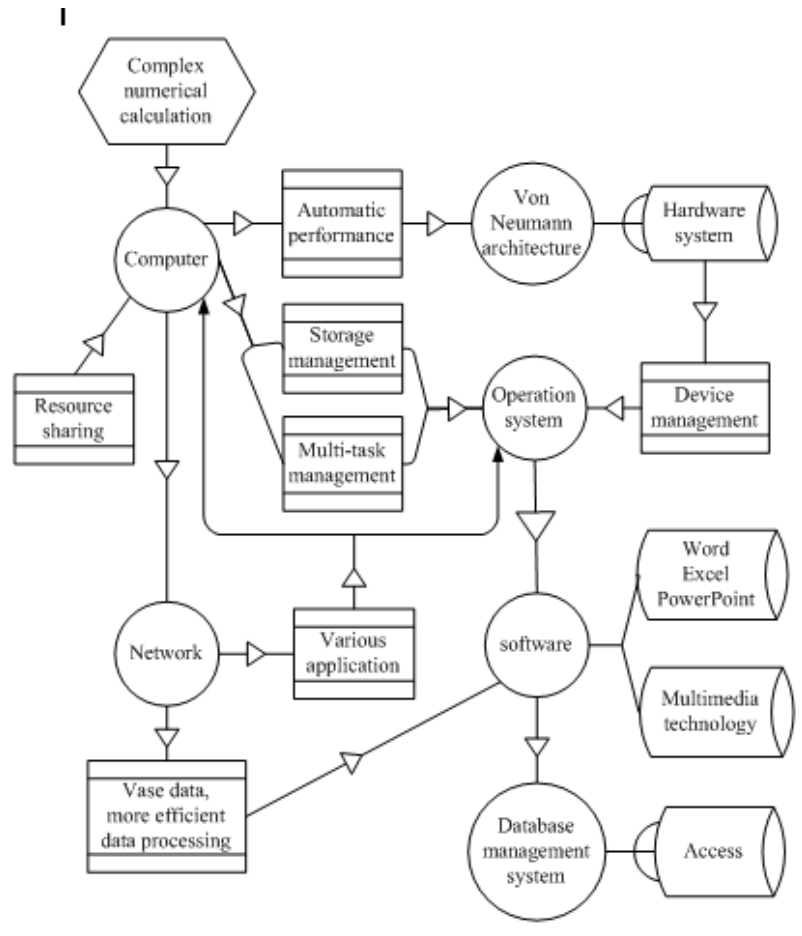

Figure 2. Process oriented knowledge map of course "Fundamental of Computer Technology"

Though course content is apparently technical for existence of utility applications, academics is a significantly clue. The existence of each application is supported by a series of theories. The theories are incarnated by the necessity, rationality and universality of utility applications. In teaching, the combination of academic knowledge and practical operation would impress upon students that principle is critical impetus for application in practice.

The current college students have superficial understanding of knowledge. They grasp mass information and clutter them without restoring order. Information on chaotic state would degenerate into useless data, and hardly convert to knowledge [5]. The reason is few college students have understanding on knowledge management, and dig tacit knowledge to capture information into personal knowledge repositories [5]. Knowledge map provides a visible normative schema of knowledge to students. Both course knowledge units and their internal and external relationship are specified in the schema [8]. Therefore, knowledge map is an effective method for student to convert tacit knowledge to explicit knowledge [9] and can promote the knowledge identify process of student.

Knowledge sharing is the core content of knowledge management. It is prerequisite to knowledge integration and knowledge appreciation. Share of knowledge occurs between entities with different knowledge level, such as student and teacher, or between entities with same knowledge level, for example, teacher and teacher. College teachers are similar knowledge entities and collective course preparation is an efficient mechanism of knowledge sharing. In collective course preparation, teachers discuss design teaching context, extract the critical knowledge point of each field, discuss the difficulty of course, and collect course case. In this process, tacit knowledge is shared among teachers. Knowledge map is one of the outcomes. Yang et al [3] researched the status of tacit knowledge sharing in university. One of subjective factors hindering tacit knowledge sharing is knowledge monopoly psychology. The objective factors hindering tacit knowledge sharing relates to the definition of intellectual property rights and lack of incentives. Hu et al [10] analyzed the measures of tacit knowledge transformation in university. This paper concluded that college teachers' self-focused thinking mode and indifference interpersonal relationship increased the cost of tacit knowledge transformation, and reduced the income of tacit knowledge transformation. All factors mentioned in [3] [10] can be overcome in teaching based on community.

\subsubsection{Pre-course survey on students}

The objective of pre-survey is to find out students' actual level of computer application. It belongs to capture process of knowledge management. The information gathered for survey would be integrated to assist teachers in adapting teaching content and teaching plan.

\subsection{Teaching process control}

Teaching content management focuses on teaching quality. Basically, students in same classroom can obtain the same explicit knowledge, but knowledge can be handled varies from their study method and professional aptitude. The status is mainly caused by the difference of knowledge management ability [5]. Zhuang et al [11] explored the status of knowledge management of college student. The obstacles to knowledge management of students were two aspects. One was chaotic mess in knowledge organization, the other was the lack of tacit knowledge capturing and sharing. Therefore, group learning and intensified curricular projects are introduced to help students in managing knowledge autonomously.

\subsubsection{Group learning and knowledge sharing}

The knowledge sharing and transfer among college students depend on a certain situation. The situation includes learning institution and learning organization, mutual trust mentality and proper incentive mechanism [11]. A group based on a common interest or problems-oriented is a good environment. The collaboration among group members can largely realize the sharing of tacit knowledge [9]. 
Students taken Fundamental of Computer Technology are grouped according to the pre-course survey. Each group contains four and five students. The student with higher operation skill acts as team leader. Before every experiment, teacher would gather team leaders together to explain typical problems. If any problem happens during the experiment, it should be solved within the group first. If the group couldn't settle it inside, then teacher comes to answer. In group learning mode, mutual trust would built in members naturally. It provides the potential to break the knowledge monopoly psychology. To enhance the communication and collaboration in team members, the experiment grade of students contains personal score, group score and contribution score for group. These measures create a healthy study atmosphere, promoting mining and transfer of tacit knowledge among the students.

\subsubsection{Intensified curricular projects and knowledge organization}

In knowledge management, knowledge integration is a critical step. The current college students have many channels to obtain knowledge, but have little capacity in merging and structuring knowledge. Lacking of the ability, knowledge cannot be orderly, automatic organized to solve problems.

Fundamental of Computer Technology provides a series of intensified curricular projects for extracurricular study. A project is across several knowledge points, requiring students to do knowledge expansion. Students should select, integrate, and handle knowledge to achieve the intensified curricular projects. The projects are accomplished by group, requiring the collaborative activities among students. Having experienced the project, students obtained both the explicit knowledge and tacit knowledge.

The investigations about self-learning achievement evaluation of students in 2012 and 2014 are illustrated in figure 3 .

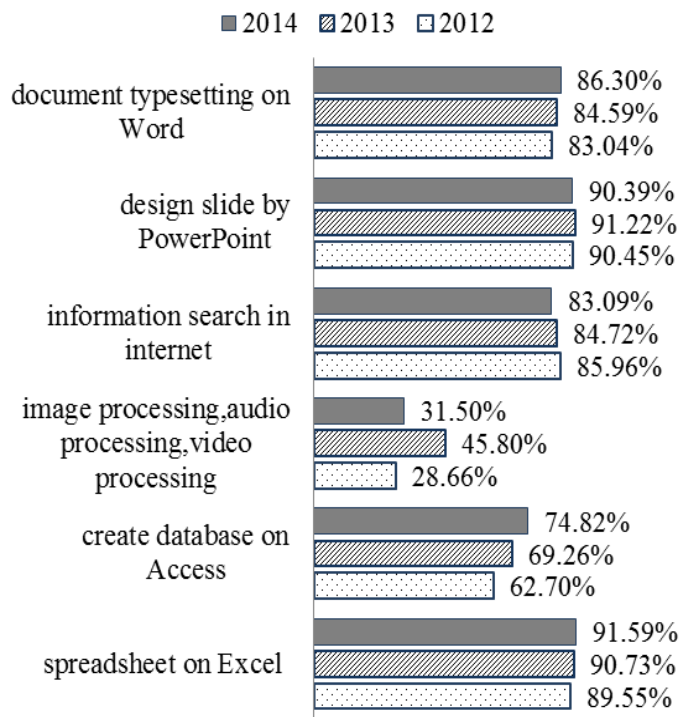

Figure 3. What knowledge have you achieved by course study? (Multiselect).

For lacking of course hour, some knowledge points are not mentioned in classroom. From figure 3, some conclusion can be got as follows:

- Students have the ability to do autonomous study.

- The intensified curricular projects complemented students' knowledge domain.

- The majority of students finished the practice on knowledge integration and acquired new knowledge.

\subsection{Teaching Summative Evaluation}

Teaching evaluation is the last phase of the closedloop architecture, includes terminal investigations and examination result analysis. It appraises the effectiveness of the course cycle, determines which teaching objectives are achieved and the extent to which targeted problems are solved, and enlightens a reform at next teaching period.

To evaluate the efficiency architecture completely, a series of investigations are applied to gather information from students. Figure 3 shows the Self-learning achievement evaluation of students from grade 2010 to grade 2012. In contrast to figure 1 , the computer application skill of students was obviously raised. The intensified curricular projects provide a platform for student's study activities, and have good effect on their personal knowledge management. Investigation on difficulty degree of course is described in figure 4. From 2012 to 2014, the percent of students found hard or easy in study was steady decline, and more than $80 \%$ students accommodated to course well. It implies that the organization of course content is appropriate and can match student's study rhythm. 

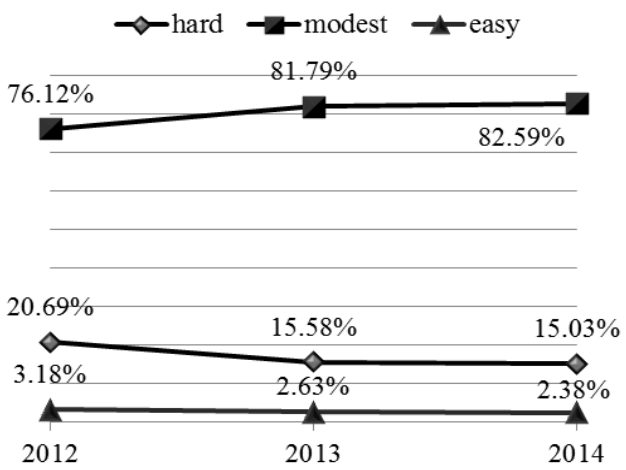

Figure 4. What do you appraise the difficulty degree of course?

To test the practical skill of students, a reform was performed on course examination mechanism. Three tests by computer instead of a final examination by hand are offered in stages. The knowledge point in present text would not appear in next test. This method reduces the load of students. At the same time, it forces students to pay special attention to study process rather than outcome. Students should plan the study schedule by themselves according to the test. This process also enhances their self-knowledge management ability. Table 1 lists the distribution of final course grade of students between 2010 and 2014 .

Table 1. Final course grade distribution (2010 2014)

\begin{tabular}{|c|c|c|c|}
\hline & 2012 & 2013 & 2014 \\
\hline $90-100$ & $23.00 \%$ & $36.42 \%$ & $8.99 \%$ \\
\hline $80-89$ & $59.13 \%$ & $46.53 \%$ & $57.82 \%$ \\
\hline $70-79$ & $14.44 \%$ & $12.39 \%$ & $25.51 \%$ \\
\hline $60-69$ & $3.00 \%$ & $4.04 \%$ & $6.66 \%$ \\
\hline $59-0$ & $0.43 \%$ & $0.61 \%$ & $0.68 \%$ \\
\hline
\end{tabular}

The percent of failed students was below $1 \%$ since 2010. The percent of student got a score in the 70 to 90 range increased by year. The final course grade distribution of 2014 matches Poisson distribution very well.

In the investigation about study motivation, the percent of students which treat the course only as a tool to pass National Computer Rank Examination has fallen to $13 \%$, illustrated in figure 5 . It indicates that curricular identity of students is increasing by year.

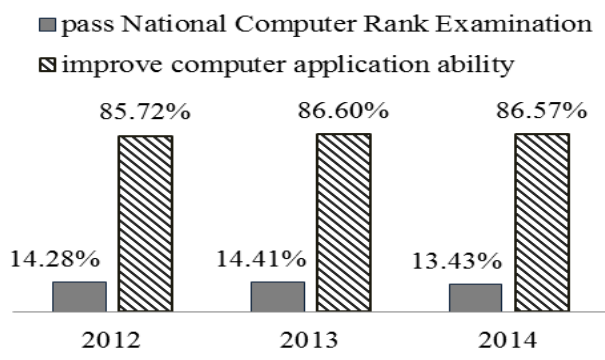

Figure 5: What do you think about the motivation of general education of computer science?

\section{CONCLUSIONS}

This paper emphasizes the importance of knowledge management for general education of computer science. A knowledge-management-based closedloop architecture is developed to quest activity of knowledge management in each teaching phase. In the teaching cycle, students are trained to do personal knowledge management which can foster their autonomous learning ability and guarantee quality of study.

\section{ACKNOWLEDGEMENTS}

The paper is supported by education reform foundation of Huazhong University of Science \&Technology under project "focus on aptitude raise in general education of computer science".

\section{REFERENCES}

[1] Zhijin, Zh. \& Wenjiao, Y. 2007.Tacit knowledge, implicit cognition and scientific creativity, Journal of Huazhong University of Science and Technology(Social Science Edition) (11):107-110.

[2] Zhijin, Zh. \& Yongming, Ch. 2001. The nature of inspiration, Journal of Exploration of psychology (20):1216.

[3] Zhenhua, Y. \& Qingfen, Sh. 2007. An exploration on obstacle and boost in sharing tacit knowledge on college, Science \& Technology Progress and Policy(24):80-84.

[4] Fairchild, A.M. 2002. Knowledge management metrics via a balanced scorecard methodology, Proceedings of the 35th Hawaii International Conference on System Sciences: USA,

[5] Fan, Zh. 2011.Knowledge management in undergraduates, Chinese Journal of Medical Library and Information Science (20):1-4.

[6] Yufang. M. \& Sijing, W. 2009. He application of knowledge map in knowledge management for college English teachers: actuality and expectation, China Educational Technology (6):22-26.

[7] Dan, L. \& Huiping, Zh. 2008. Research on the theory of knowledge map, Sci-Tech Information Development \& Economy (18):130-132.

[8] Miao, Zh. \& Zhiping, F. 2003. Knowledge map: an effective tool for knowledge management and organizational learning, industrial engineering and management (3):56-60.

[9] Xiaoju, Y. \& Qingyun, W. 2009. An exploration on college students' explicit knowledge management strategy, Journal of Jiangxi Radio \& TV University (4): 13-17

[10]Zeping, H. \& Qinfen, Sh. 2006. The transformation of tacit knowledge and rational choice, Journal of Soft Science (15):103-105.

[11]Wei, Zh. 2008. The obstacle in knowledge sharing of undergraduate, Education Exploration (203):14-16. 